\title{
On the amplitude and regulation of the internal $P$ loading from anoxic bottoms in the Baltic proper.
}

\section{ANDERS STIGEBRANDT}

\author{
University of Gothenburg
}

Presenting Author: anders.stigebrandt@marine.gu.se

Knowing the external phosphorus $\mathrm{P}$ supply EPS and the dynamics controlling internal sources and sinks of $P$, the year-toyear evolution of the winter $\mathrm{P}$ concentration $c 1$ in the surface layer of a basin may be estimated using a time-dependent $\mathrm{P}$ budget model. In a $\mathrm{P}$ model of the Baltic proper, the internal $\mathrm{P}$ source IPS from anoxic bottoms of area Aanox $\left(\mathrm{km}^{2}\right)$ is parameterized as $I P S=f_{s} \cdot$ Aanox, where $f_{s}$ is the specific P flux. The total sink TPsink is parameterized as proportional to $c 1$, thus TPsink $=c 1 \cdot T R V F$ where TRVF is the annual Total Removal Volume Flux $\left(\mathrm{km}^{3}\right.$ year $\left.{ }^{-1}\right)$. Using the method of least squares and 47-years-long time series of EPS and of clobs, the volume weighted observed $\mathrm{P}$ concentration in the surface layer in winter, it is found that the combination $f_{S}=1.22$ (tonnes $\mathrm{km}^{-2}$ year $^{-1}$ ) and $T R V F=3000\left(\mathrm{~km}^{3}\right.$ year $\left.{ }^{-1}\right)$ gives the best fit between the modelled clmod and the observed clobs winter surface concentrations. With these values of $f s$ and $T R V F$, the model describes the observed evolution of $c 1$ very well (Stigebrandt \& Andersson, Frontiers in Marine Science, 7:572994). The present estimate of $f_{s}$ gives the spatial and temporal average rate of $\mathrm{P}$ diffusion from anoxic sediments to the bottom water in the Baltic proper.

The chosen parameterization of the internal source IPS simulates the filtering effect exerted by iron oxides on phosphorus (PO4) fluxes in the top layer of the sediment. PO4, produced by decomposition of organic matter in the sediment, is adsorbed to iron oxides when reaching the oxidized top layer of the sediment and thereby stay in the sediment. However, if the bottom water becomes anoxic, also the top layer of the sediment becomes anoxic whereby iron oxides are reduced and the associated PO4 is set free. The filtering effect thus vanishes and PO4 may diffuse into the bottom water. The diffusion of PO4 from the sediment to the bottom water under anoxic conditions is initially strong and thereafter declining. Possible improvements of the parameterization of IPS will be discussed. 